\title{
Stroke-Like Migraine Attacks after Radiation Therapy (SMART) Syndrome Is Not Always Completely Reversible: A Case Series
}

\author{
D.F. Black, J.M. Morris, E.P. Lindell, K.N. Krecke, G.A. Worrell, J.D. Bartleson, and D.H. Lachance
}

\begin{abstract}
SUMMARY: We retrospectively reviewed clinical and imaging findings in 11 patients with stroke-like migraine attacks after radiation therapy (SMART) syndrome to better understand this disorder previously thought to be reversible. Six men and 5 women had complex bouts of neurologic impairment beginning, on average, 20 years after cerebral irradiation. All had characteristic, unilateral gyriform enhancement on MR imaging that developed within 2-7 days and typically resolved in 2-5 weeks. Unlike prior reports, $45 \% \mathrm{had}$ incomplete neurologic recovery manifesting as dysphasia, cognitive impairment, or hemiparesis. The remaining $55 \%$ recovered completely over an average of 2 months. Three of 11 patients developed cortical laminar necrosis. Brain biopsies in 4 of 11 did not demonstrate a specific pathologic substrate. These additional 11 patients contribute to the understanding of variability in stroke-like migraine attacks after radiation therapy syndrome, which often but not uniformly manifests with headaches and seizures, demonstrates a typical evolution of imaging findings, and may result in permanent neurologic and imaging sequelae.
\end{abstract}

ABBREVIATIONS: SMART = stroke-like migraine attacks after radiation therapy; $\mathrm{CLN}=$ cortical laminar necrosis; $\mathrm{CJD}=\mathrm{Creutzfeldt-Jakob}$ disease; PIPG $=$ peri-ictal pseudoprogression

$\mathbf{S}$ troke-like migraine attacks after radiation therapy (SMART) is a syndrome presumed to be a delayed complication of whole-brain irradiation wherein patients have recurrent attacks of complex neurologic signs and symptoms, often including headache and seizures that start many years after radiation therapy and demonstrate characteristic imaging findings. ${ }^{1-5}$ Patients may or may not have an antecedent history of migraine headaches or seizures. Attacks are typically subacute in onset and involve stroke-like deficits such as homonymous hemianopsia, hemiplegia, aphasia, and/or seizures. In all reported cases thus far, symptoms have been debilitating but ultimately resolve completely, usually after weeks. MR imaging findings that correlate with these clinical manifestations include unilaterally increased T2 signal within temporal, parietal, or occipital cortices and an exuberant, thick, gyral cortical gray matter enhancement that disappears as symptoms resolve. The MR imaging findings do not respect vascular borders.

Although SMART appears to be a delayed consequence of re-

Received January 4, 2013; accepted after revision March 4.

From the Departments of Radiology (D.F.B., J.M.M., E.P.L., K.N.K.) and Neurology (G.A.W., J.D.B., D.H.L.), Mayo Clinic, Rochester, Minnesota.

Paper previously presented at: Annual Meeting of the American Society of Neuroradiology, April 23, 2012; New York, New York.

Please address correspondence to David F. Black, MD, Mayo Clinic, E2 Radiology, 200 First St SW, Rochester, MN 55905; e-mail: black.david@mayo.edu

http://dx.doi.org/10.3174/ajnr.A3602 mote cerebral irradiation, the pathophysiology is unknown and pathologic specimens have not been previously reported.

Between March 1, 2006, and March 1, 2012, the authors observed 11 patients in their daily practice who met the proposed diagnostic criteria for SMART and underwent head MR imaging while symptomatic. ${ }^{1}$ We obtained approval from our internal review board to retrospectively report the clinical, pathologic, and imaging findings of these patients.

\section{Case Series}

The 11 subjects ranged in age from 37-60 years (mean, 50 years) at the time of diagnosis with SMART. All had received cerebral irradiation for various indications many years before onset of the clinical syndrome (Table 1). Table 2 describes the frequency of their presenting signs and symptoms. Each patient was retrospectively included in this study only after completing a comprehensive neurologic and medical evaluation at our institution that excluded other alternative diagnostic possibilities. Interval between radiation therapy and SMART diagnosis ranged from 6-30 years (mean, 20), and the average age at the time of radiation therapy was 30 years. Six patients (55\%) had more than 1 SMART episode. Five patients ( $45 \%$ ) had a seizure history before SMART episodes, $8(72 \%)$ patients had interictal epileptiform activity recorded on EEG, 4 (36\%) had focal electrographic seizures recorded, and 2 patients had only focal slowing (Table 3). Four patients (37\%) had recurrent severe migrainous headaches before SMART episodes, 


\begin{tabular}{|c|c|c|c|c|c|c|c|c|}
\hline Patient & Radiation Indication & Interval, y & Age at Diagnosis, $y$ & $\begin{array}{l}\text { Seizures } \\
\text { Before }\end{array}$ & $\begin{array}{l}\text { Seizure } \\
\text { With }\end{array}$ & $\begin{array}{l}\text { Headache } \\
\text { Before }\end{array}$ & $\begin{array}{l}\text { Headache } \\
\text { With }\end{array}$ & Therapies Used \\
\hline 1 & Pituitary lesion & 22 & 60 & $?$ & $\mathrm{Y}$ & $\mathrm{N}$ & $\mathrm{N}$ & Phenytoin, levetiracetam \\
\hline 2 & Pineal tumor & 30 & 42 & $\mathrm{Y}$ & $\mathrm{N}$ & $?$ & $\mathrm{Y}$ & Corticosteroids \\
\hline 3 & Astrocytoma & 32 & 44 & $\mathrm{~N}$ & $\mathrm{~N}$ & $?$ & Y & Verapamil, phenytoin \\
\hline 4 & Oligoastrocytoma & 14 & 53 & Y & $\mathrm{Y}$ & $\mathrm{N}$ & $\mathrm{N}$ & Phenytoin, levetiracetam \\
\hline 5 & Dysgerminoma & 19 & 50 & $\mathrm{~N}$ & $\mathrm{~N}$ & $\mathrm{Y}$ & $\mathrm{Y}$ & Corticosteroids \\
\hline 6 & Fibrillary astrocytoma & 13 & 45 & Y & Y & $\mathrm{N}$ & $\mathrm{N}$ & $\begin{array}{l}\text { Levetiracetam, valproate, } \\
\text { corticosteroids }\end{array}$ \\
\hline 7 & Astroblastoma & 27 & 58 & Y & $\mathrm{N}$ & $\mathrm{N}$ & Y & Phenytoin, aspirin \\
\hline 8 & Lymphoma & 16 & 37 & $\mathrm{~N}$ & Y & Y & Y & Levetiracetam, verapamil, aspirin \\
\hline 9 & Óligoastrocytoma & 10 & 50 & $\mathrm{~N}$ & Y & Y & Y & $\begin{array}{l}\text { Levetiracetam, verapamil, } \\
\text { corticosteroids }\end{array}$ \\
\hline 10 & Metastatic melanoma & 6 & 50 & Y & Y & $\mathrm{N}$ & Y & $\begin{array}{l}\text { Levetiracetam, verapamil, } \\
\text { corticosteroids }\end{array}$ \\
\hline 11 & Brain stem glioma & 30 & 58 & $\mathrm{~N}$ & Y & $\mathrm{Y}$ & Y & Levetiracetam, verapamil \\
\hline
\end{tabular}

Note:- "Interval" indicates the interval in years between radiotherapy and the diagnosis of SMART. "Seizures before" and "Seizure with," "Headache before" and "Headache with" refer to symptoms preceding initiation and during SMART episodes, respectively.

Table 2: SMART presenting signs and symptoms

\begin{tabular}{lcr}
\hline \multicolumn{1}{c}{ Signs and Symptoms } & No. of Cases & $\%$ \\
\hline $\begin{array}{l}\text { Interictal epileptiform activity, } \\
\quad \text { electrographic seizures, }\end{array}$ & $9 / 11$ & 82 \\
$\quad$ or clinical seizure activity & & \\
Headache & & 73 \\
Speech disturbance & $8 / 11$ & 64 \\
Visual field defect & $7 / 11$ & 64 \\
Altered mentation & $7 / 11$ & 45 \\
Hemiparesis & $5 / 11$ & 45 \\
Hemisensory change & $5 / 11$ & 18 \\
\hline
\end{tabular}

${ }^{a}$ Interictal epileptiform spikes, sharp waves, electrographic seizures, or witnessed seizure. One of the patients without EEG interictal epileptiform activity had a witnessed convulsion.

Table 3: EEG results during SMART symptoms

\begin{tabular}{|c|c|}
\hline Patient & EEG Results \\
\hline 1 & $\begin{array}{l}\text { Electrographic seizure activity over the right } \\
\text { temporal region }\end{array}$ \\
\hline 2 & $\begin{array}{l}\text { Potentially epileptogenic discharges over the left } \\
\text { temporal region }\end{array}$ \\
\hline 3 & $\begin{array}{l}\text { Potentially epileptogenic discharges over bilateral } \\
\text { temporal regions }\end{array}$ \\
\hline 4 & $\begin{array}{l}\text { Electrographic seizure activity over the left } \\
\text { temporal region }\end{array}$ \\
\hline 5 & Focal slowing over the right hemisphere \\
\hline 6 & $\begin{array}{l}\text { Electrographic seizure activity over the left } \\
\text { temporal region }\end{array}$ \\
\hline 7 & Focal slowing over the left occipito-parietal region \\
\hline 8 & $\begin{array}{l}\text { Potentially epileptogenic discharges over the right } \\
\text { frontal region (note: left temporo-parietal MRI changes) }\end{array}$ \\
\hline 9 & $\begin{array}{l}\text { Potentially epileptogenic discharges over the } \\
\text { midline, right parietal, and bilateral temporal regions }\end{array}$ \\
\hline 10 & $\begin{array}{l}\text { Electrographic seizure activity over the right } \\
\text { parietal region }\end{array}$ \\
\hline 11 & $\begin{array}{l}\text { No potentially epileptogenic activity on EEG but } \\
\text { had witnessed generalized seizure }\end{array}$ \\
\hline
\end{tabular}

Note:-Eight patients (72\%) had epileptiform activity recorded with EEG and 4 (36\%) had focal electrographic seizures recorded.

and $8(73 \%)$ had migraine-like headaches as part of their SMART presentation.

All patients demonstrated the typical gyriform, unilateral cortical gadolinium enhancement with minimal leptomeningeal enhancement that is characteristic of SMART as well as the correlative abnormal T2 and FLAIR signal with mild mass effect (Fig 1).
Although the radiation dose received was not known in most cases, we believe that the MR imaging findings were in regions that were included in the radiation ports. There was prominent involvement of the temporo-parietal and occipital lobes with relative sparing of the frontal lobes in all cases. Gyriform enhancement began 2-7 days after the initiation of neurologic signs and symptoms and typically resolved in $2-5$ weeks but lasted from 11-84 days. Gadolinium T1-weighted images demonstrated the most conspicuous findings followed by FLAIR images.

Three patients $(27 \%)$ developed cortical laminar necrosis (CLN) involving the same regions seen to enhance (Table 2). In case 2, CLN developed 17 days after symptoms began (Fig 2). No diffusion restriction was evident in the regions of enhancement or CLN.

The clinical course in cases 1,9 , and 10 was complicated by a superimposed cerebral infarction and symptoms of stroke (Figs 3 and 4). Each of these infarctions occurred within a subregion of the more typical changes of SMART in the right occipital lobe. In patients 1 and 9, right occipital infarctions were discovered in regions of resolved gyriform enhancement that had been present 7 and 9 days previously, respectively. There had been no evidence of restricted diffusion on the prior examinations. Patient 10 presented with a generalized seizure and had a new right occipital infarct with adjacent gyriform enhancement and cortical edema in the right temporoparietal and occipital lobes. Patients 9 and 10 went on to have full clinical recovery documented in the medical record. The residual deficits in patient 1 were not anatomically correlated to the region of infarction.

Patient 1 was initially diagnosed with Creutzfeldt-Jakob Disease (CJD) because of an elevated CSF 14-3-3 protein, but, over the next month, her neurologic status improved and she was able to walk short distances. Eventually, she was able to return home, though she required greater assistance from her husband with activities of daily living. She had no new neurologic difficulties for the next 5 years of follow-up.

Five patients (45\%) demonstrated various degrees of multiple magnetic susceptibility foci most compatible with cavernomas, probably a consequence of prior radiation therapy.

Various medications were used in the care of these patients, most commonly levetiracetam, which appeared to improve sei- 

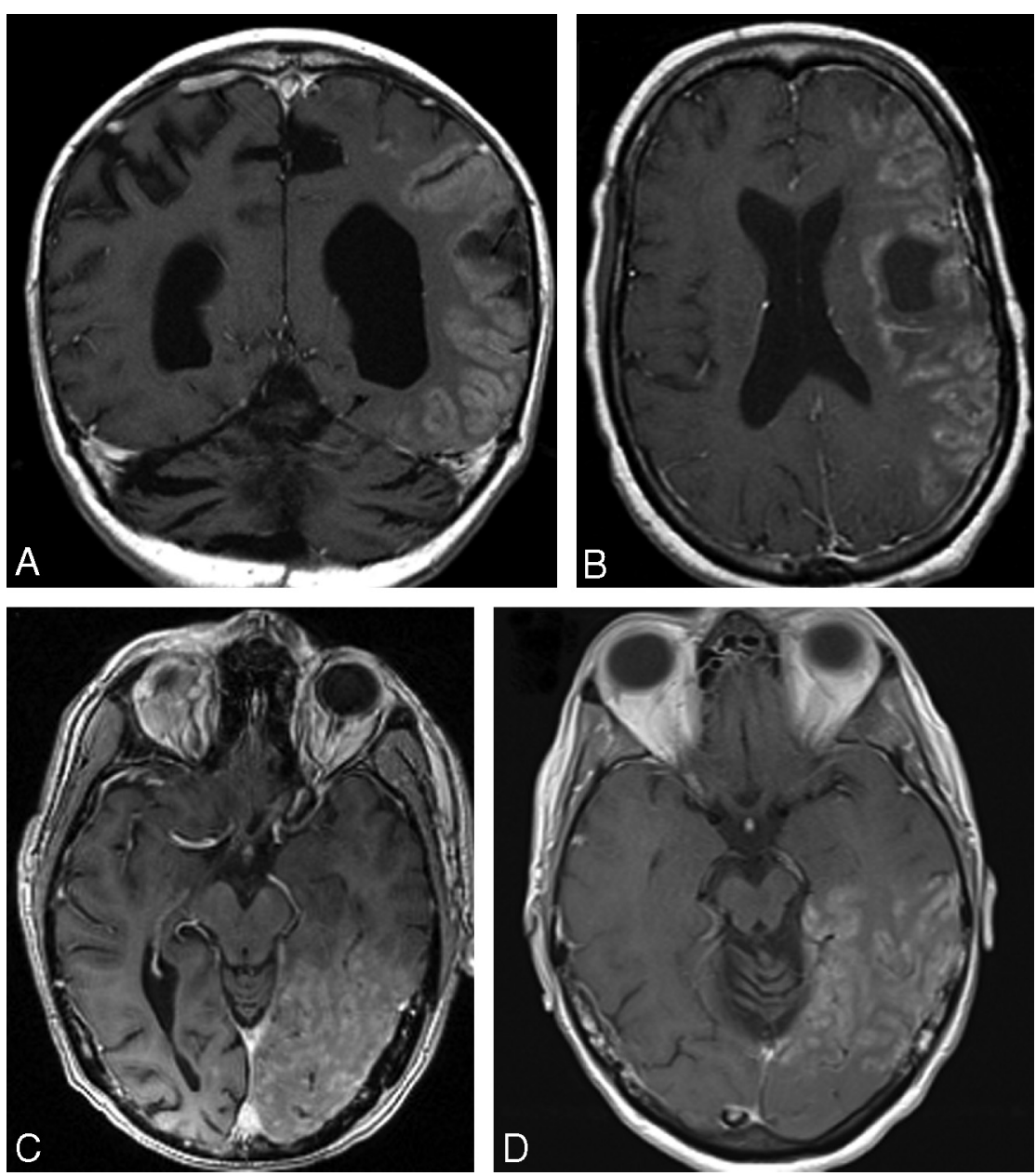

FIG 1. $A$, Patient $3 ; B$, patient 4 ; $C$, patient $7 ; D$, patient 11. T1-weighted images with gadolinium enhancement demonstrate typical patterns of enhancement seen in SMART.
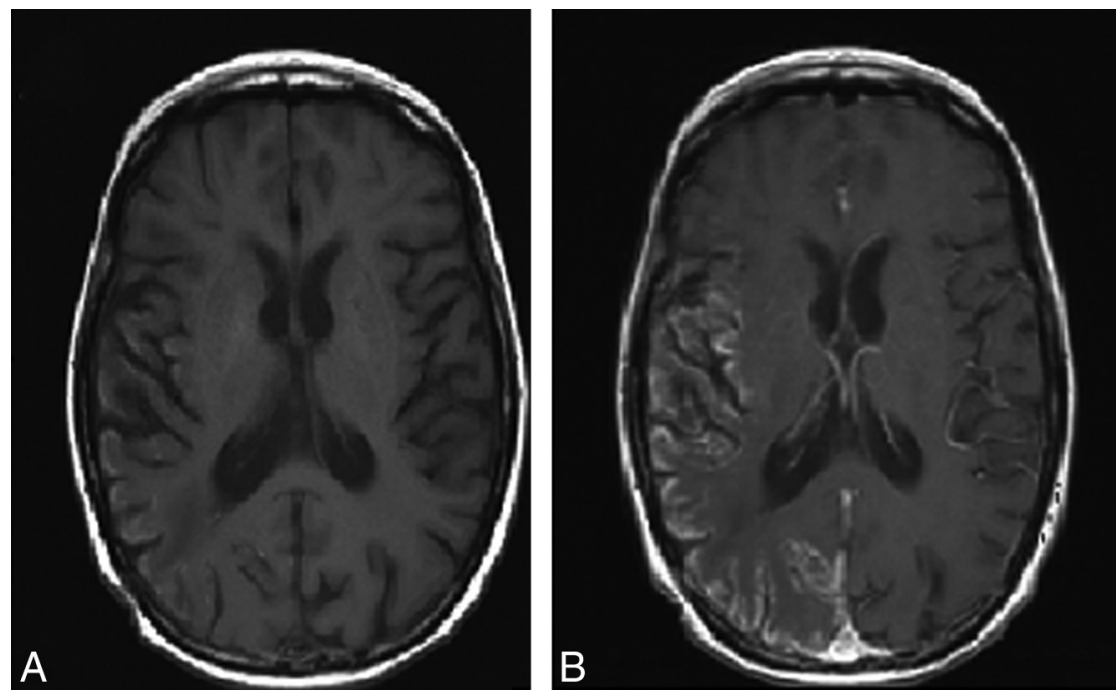

FIG 2. Patient 2. A, T1-weighed image without gadolinium demonstrates typical findings of right temporoparietal cortical laminar necrosis on day 17 of symptoms. B, Tl-weighted image with gadolinium demonstrates concordant unilateral gyriform enhancement on the same examination.

zure control in several patients. Patient 2 was treated with a 3-month steroid taper and began to improve within the first week, though she did not return to her baseline. Three patients (patients
1, 2, and 5) had transient problems with sodium and water balance during their symptoms.

Four patients (36\%) had brain biopsies because of concerns of tumor recurrence. All demonstrated mild, nonspecific gliosis without a specific pathologic substrate for SMART or evidence of recurrent tumor.

Six patients $(55 \%)$ recovered completely back to their antecedent clinical baseline, with recovery taking 1.5-2.5 months (mean, 2). Five patients (45\%) showed gradual but incomplete recovery with residual deficits most often including dysphasia, cognitive impairment, and mild hemiparesis (Table 4).

\section{DISCUSSION}

This series provides several new insights into the poorly understood and possibly under-recognized syndrome of SMART. Prior publications described a benign natural history with complete return to clinical baseline; however, in this series, $45 \%$ of patients had incomplete clinical recovery. All the patients in this series met the proposed diagnostic criteria of SMART, except for this unexpected incomplete recovery. ${ }^{1}$ Permanent imaging sequelae from SMART were demonstrated in $27 \%$, with MR imaging findings typical of cortical laminar necrosis developing as early as 17 days after symptom onset.

We demonstrated that the thick gyriform cortical enhancement characteristic of SMART develops only after 2-7 days, typically resolves in 14-35 days, but may last between 11-84 days. Diffusion-weighted abnormalities were minimal and primarily demonstrated T2 shine through without convincing evidence of restricted diffusion except in the 3 cases that had superimposed infarcts. The small occipital infarcts seen in patients 1 and 9 occurred after the more typical changes of gyral edema and enhancement had resolved, again suggesting that the mechanisms causing SMART are complex. A process driven by some form of cerebral hyperexcitability with impaired autoregulatory parameters and endothelial damage occurring as a consequence of remote radiation therapy seems plausible. Stabilizing seizure threshold and vascular reactivity are logical therapeutic interventions to consider. 

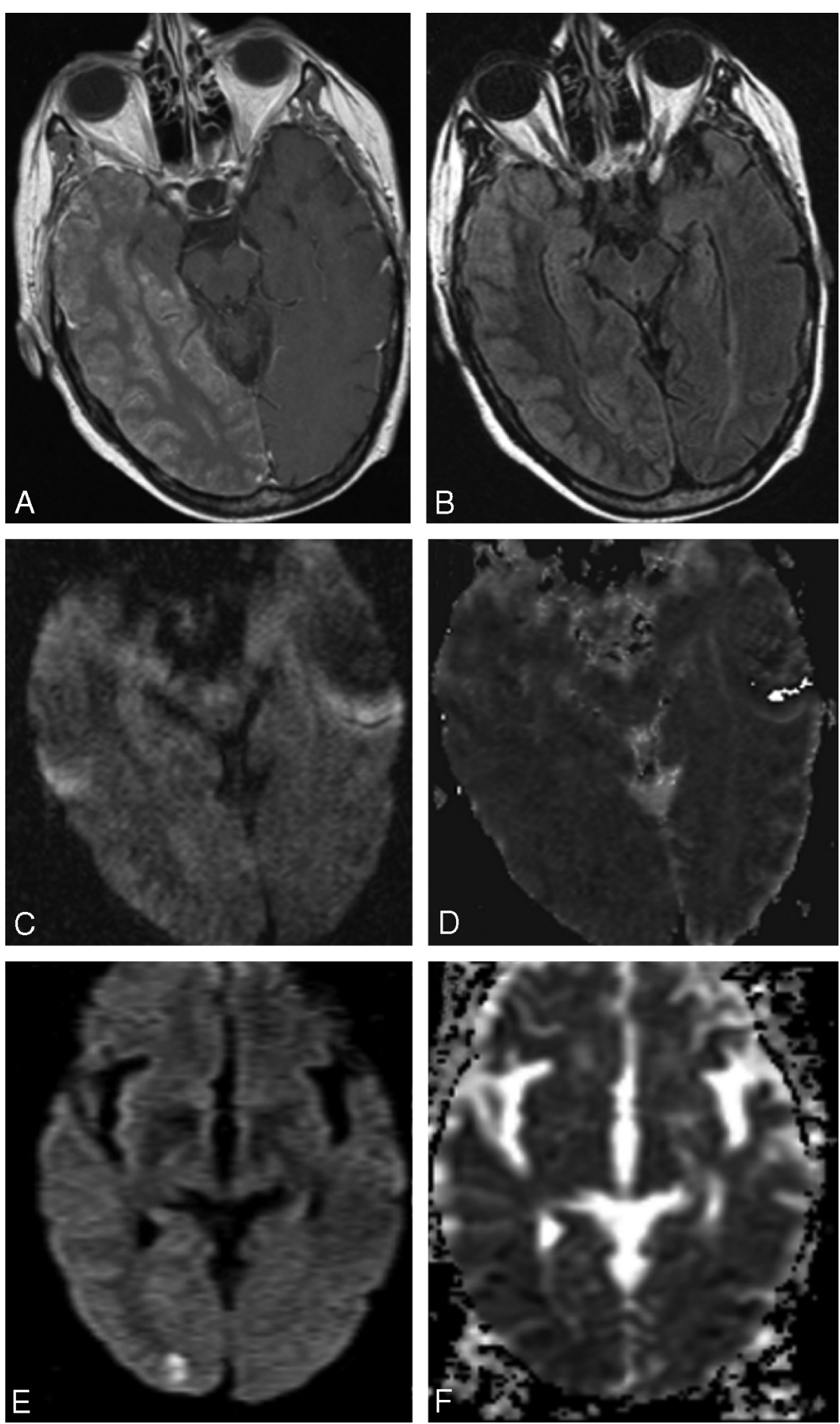

FIG 3. Patient 1. A, Gadolinium-enhanced $\mathrm{T} 1$ image demonstrating characteristic unilateral, thick gyriform enhancement during an episode of SMART. B, FLAIR sequence showing gyral T2 signal that corresponds to the regions of enhancement. $C$ and $D$, Diffusion-weighted sequence and ADC map demonstrate no convincing diffusion restriction upon initial presentation until 7 days later ( $E$ and $F$ ), when enhancement resolved but a new right occipital infarction was found.

The pathologic substrate for SMART is unknown, and biopsy in 4 of the 11 patients (36\%) failed to demonstrate pathologic etiology. Also, 3 of 11 patients in this series had comorbid problems with high or low sodium or diabetes insipidus, but to what extent this may have contributed is not known.
Similar to previous reports, the interval between radiation and SMART diagnosis was on average 20 years, with an average age at diagnosis of $50 .{ }^{1,3}$ All patients had somatosensory findings, $82 \%$ had various levels of evidence of seizure activity temporally and spatially correlated with imaging findings, $73 \%$ had migraine-like headaches, and all had unilateral, thick gyriform enhancement during their symptoms.

Limitations of this series include its retrospective nature. We did not actively recruit suspected cases but simply came across them during our daily practice. We saw 1-2 cases per year at our tertiary care center. Many of the subjects had received radiation therapy many years previously at other institutions; thus, radiation doses were largely unknown, though the radiation ports probably included regions affected by SMART in all cases.

Inherent to their history of cerebral irradiation and tumor, patients with SMART may have seizures as a premorbid condition and possible contributor to their neurologic problems. Many reports have demonstrated that nonconvulsive status epilepticus or frequent partial seizures may produce transient cortical edema, T2 hyperintensity, leptomeningeal or cortical enhancement, and permanent sequelae, including cortical laminar necrosis. ${ }^{6-9}$ Postictal MR imaging findings in patients without prior radiation therapy appear different from SMART, suggesting that SMART may represent a unique syndrome with a complex poorly understood pathophysiology occurring in a subset of patients long after radiation therapy. ${ }^{10,11}$

It may be that seizures in patients with SMART strain an already impaired brain because of the chronic endothelial vascular damage caused by remote radiation, and this "double hit" produces infarction in some instances in the affected cortical areas. Whether seizures initiate or are a consequence of SMART, the combination of radiation-induced vascular damage and clinical and subclinical seizure activity could explain cortical edema and impaired blood-brain barrier integrity with persisting contrast enhancement for days to weeks while patients' symptoms outlast any particular seizure activity and, at times, become permanent with evidence of cortical laminar necrosis. 

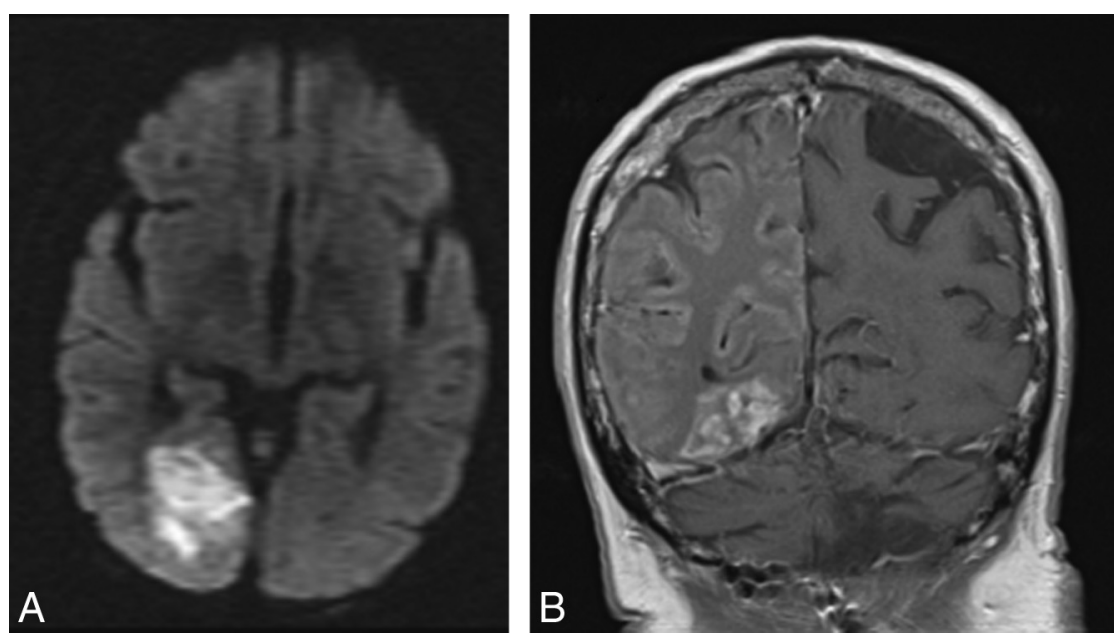

FIG 4. Patient 10. A, Acute right occipital infarction with restricted diffusion. $B, T 1$ gadoliniumenhanced coronal image demonstrates the subacute enhancement of the infarction with more extensive gyral enhancement throughout the right temporoparietal region. Postoperative changes in the left cerebellum from prior melanoma resection.

Table 4: Correlations between Radiologic Findings, Biopsy, and Recovery

\begin{tabular}{cccccl}
\hline Patient & CLN & DWI & Biopsy & Stroke & Recovery \\
\hline 1 & $\mathrm{~N}$ & $\mathrm{~N}$ & $\mathrm{Y}$ & $\mathrm{Y}$ & Incomplete \\
2 & $\mathrm{Y}$ & $\mathrm{N}$ & $\mathrm{N}$ & $\mathrm{N}$ & Incomplete \\
3 & $\mathrm{~N}$ & $\mathrm{~N}$ & $\mathrm{~N}$ & $\mathrm{~N}$ & 2 mo \\
4 & $\mathrm{~N}$ & $\mathrm{~N}$ & $\mathrm{~N}$ & $\mathrm{~N}$ & $1-2$ mo \\
5 & $\mathrm{Y}$ & $\mathrm{N}$ & $\mathrm{Y}$ & $\mathrm{N}$ & Incomplete \\
6 & $\mathrm{~N}$ & $\mathrm{~N}$ & $\mathrm{~N}$ & $\mathrm{~N}$ & 2.5 mo \\
7 & $\mathrm{~N}$ & $\mathrm{~N}$ & $\mathrm{Y}$ & $\mathrm{N}$ & Incomplete \\
8 & $\mathrm{~N}$ & $\mathrm{~N}$ & $\mathrm{Y}$ & $\mathrm{N}$ & Incomplete \\
9 & $\mathrm{~N}$ & $\mathrm{~N}$ & $\mathrm{~N}$ & $\mathrm{Y}$ & 2 mo \\
10 & $\mathrm{Y}$ & $\mathrm{Y}$ & $\mathrm{N}$ & $\mathrm{Y}$ & 2.5 mo \\
11 & $\mathrm{~N}$ & $\mathrm{~N}$ & $\mathrm{~N}$ & $\mathrm{~N}$ & 2 mo \\
\hline
\end{tabular}

Note:- "Y" and "N" indicate "Yes" or "No," respectively. DWI indicates whether restricted diffusion was seen in the region of abnormal gyral edema and enhancement on the initial MR images (patients 1 and 9 subsequently had small foci of restricted diffusion after the other findings resolved). The stroke column indicates whether a stroke occurred during the same symptomatic epoch as the SMART symptoms.

Reports of what has been subsequently termed peri-ictal pseudoprogression (PIPG) demonstrate MR imaging findings similar to SMART but highlight absence of headache, less significant neurologic impairment, and more rapid clinical recovery as differentiating aspects. ${ }^{12}$ Although PIPG probably represents the same spectrum of phenomena as SMART, reported cases tend to show more meningeal enhancement than the cortical enhancement seen in SMART.

Endothelial damage may also explain the interplay between too much or too little synaptic activity producing the migrainous headaches that occur in some patients with SMART as well as the unilaterality of the imaging findings that are similar to those reported in familial hemiplegic migraine. ${ }^{13}$ Cha et $\mathrm{al}^{14}$ reported identical twins with hemiplegic migraine without evidence of seizures who had MR imaging findings identical to SMART, though no history of radiation was mentioned. Therefore, vascular endothelial damage complicating radiation therapy may lower the threshold required to develop episodic symptoms of a hyperexcitable nervous system similar to the postulated mechanism of hemiplegic migraine and could contribute to the expression of symptoms consistent with migraine in these cases. Furthermore, it is plausible to consider that this syndrome occurs in individuals who survive radiation therapy and have a genetic predisposition similar to hemiplegic migraine.

Rapid control of seizure activity, if present, is important in treating patients with SMART. Intravenous fosphenytoin, oral or intravenous levetiracetam, and a short course of high-dose corticosteroids appear to be candidates for treatment. ${ }^{15}$ Because of the ischemic nature of the MR imaging findings that can progress to cortical laminar necrosis, verapamil appears to be an intuitive, though unproven, therapeutic option that may have the benefit of also preventing headaches. Although also unproven, some form of antiplatelet therapy or even statin therapy seem to be intuitive potential treatment options.

The possibility of recurrent tumor or loss of seizure control as a cause of symptoms is omnipresent in patients with prior radiation for brain tumors, and ongoing aggressive surveillance is required. Awareness and recognition of SMART syndrome signs, symptoms, imaging findings, and recurrent attacks should serve to guard against rendering an incorrect dire prognosis and prevent aggressive interventions such as brain biopsy or cerebral angiography. All 4 patients who underwent biopsy in this series experienced incomplete recovery, and only 1 of the 7 patients who did not undergo biopsy had an incomplete recovery. It should be noted that no new signs or symptoms were temporally correlated with the biopsy procedures; thus, the relation between biopsy and clinical outcome is unknown. It is unclear why the 14-3-3 protein was elevated in patient 1 , who ultimately did not have CJD, but false-positives have been found with other nonspecific encephalopathies, especially with ischemia. ${ }^{16}$

For appropriate diagnosis and treatment, it is important for clinicians and radiologists to be aware of the characteristic imaging findings of SMART as well as their temporal evolution, the association with seizures, the possibility of permanent sequelae, and the lack of benefit and possible detriment from brain biopsy.

\section{REFERENCES}

1. Black DF, Bartleson JD, Bell ML, et al. SMART: stroke-like migraine attacks after radiation therapy. Cephalalgia 2006;26:1137-42

2. Bartleson JD, Krecke KN, O’Neill BP, et al. Reversible, strokelike migraine attacks in patients with previous radiation therapy. Neuro-Oncology 2003;2:121-27

3. Pruitt A, Dalmau J, Detre J, et al. Episodic neurologic dysfunction with migraine and reversible imaging findings after radiation. $\mathrm{Neu}$ rology 2006;67:676-78

4. Partap S, Walker M, Longstreth WT, et al. Prolonged but reversible migraine-like episodes long after cranial irradiation. Neurology 2006;66:1105-07

5. Cordato DJ, Brimage P, Masters LT, et al. Post-cranial irradiation syndrome with migraine-like headaches, prolonged and revers- 
ible neurological deficits and seizures. $J$ Clin Neurosci 2006;13:586-90

6. Cohen-Gadol AA, Britton JW, Worrell GA, et al. Transient cortical abnormalities on magnetic resonance imaging after status epilepticus: case report. Surg Neurol 2004;61:479-82

7. Sammaritano M, Andermann F, Melanson D, et al. Prolonged focal cerebral edema associated with partial status epilepticus. Epilepsia 2007;26:334-39

8. Donaire A, Carreno M, Gomez B, et al. Cortical laminar necrosis related to prolonged focal status epilepticus. J Neurol Neurosurg Psychiatry 2006;77:104-06

9. Henry TR, Drury I, Brunberg JA, et al. Focal cerebral magnetic resonance changes associated with partial status epilepticus. Epilepsia 1994;35:35-41

10. Hormigo A, Liberato B, Lis E, et al. Nonconvulsive status epilepticus in patients with cancer. Arch Neurol 2004;61:362-65

11. Quan D, Hackney DB, Pruitt AA, et al. Transient MRI enhancement in a patient with seizures and previously resected glioima: use of MRS. Neurology 1999;53:211-13

12. Rheims S, Ricard D, van den Bent M, et al. Peri-ictal pseudoprogression in patients with brain tumor. Neuro-Oncology 2011;13:775-82

13. Black DF, Kung S, Sola CL, et al. Familial hemiplegic migraine, neuropsychiatric symptoms, and Erdheim-Chester. Dis Headache 2004;44:911-15

14. Cha Y-H, Millett D, Kane M, et al. Adult-onset hemiplegic migraine with cortical enhancement and oedema. Cephalalgia 2007;27:1166-70

15. Abend NS, Florance N, Finkel RS, et al. Intravenous levetiracetam terminates refractory focal status epilepticus. Neurocrit Care 2009; 10:83

16. Collins S, Boyd A, Fletcher A, et al. Creutzfeldt-Jakob disease: diagnostic utility of 14-3-3 protein immunodetection in cerebrospinal fluid. J Clin Neurosci 2000;7:203-08 